\section{TP Periodica Polytechnica Civil Engineering}

\author{
62(2), pp. 373-385, 2018 \\ https://doi.org/10.3311/PPci.10419 \\ Creative Commons Attribution (1)
}

\title{
Evaluating the Behaviour Factor of Medium Ductile SMRF Structures
}

\author{
Djamal Yahmi ${ }^{1 *}$, Taïeb Branci ${ }^{1}$, Abdelhamid Bouchair ${ }^{2,3}$ \\ and Eric Fournely ${ }^{2,3}$
}

RESEARCH ARTICLE

Received 16 December 2016; Revised 09 May 2017; Accepted 14 November 2017

\begin{abstract}
In seismic codes, the capacity of structures is calculated using capacity design procedure based on the concept of base shear. The critical parameter in this procedure is the behaviour factor (q-factor), which allows designing the structures at the ultimate limit state accounting for their ductility and reserve strength. In this paper, the q-factor is evaluated for medium ductile steel moment-resisting frames (SMRF) using pushover analysis. The influence of specific parameters, such as the stories number, the "Column/Beam" capacity and the local response of structural members, is studied. The results show that the most important parameter that affects the q-factor is the local response of first-storey columns, while the "Column/ Beam" capacity has a less effect on this factor. Furthermore, it is observed that the q-factor value assigned to the studied frames in Eurocode-8 is systematically underestimated for low-rise frame, while the use of this value for high-rise frame is potentially unsafe.
\end{abstract}

\section{Keywords}

behaviour factor, reserve strength, ductility, steel momentresisting frames, pushover analysis

\footnotetext{
1 Department of Civil Engineering, Faculty of Civil Engineering and Architecture, University Hassiba Benbouali of Chlef, Hai As-salem, BP 151, UHB 02000 Chlef, Algeria

2 Department of Civil Engineering,

Université Clermont Auvergne, Institut Pascal, BP 10448, F-63000 Clermont-Ferrand, France 3 CNRS, UMR 6602, Institut Pascal, 63171, Aubière, France

*Corresponding author, email: yahmi_djamel@hotmail.fr
}

\section{Introduction}

The main difficulty affecting the calculation of the temporal response of a structure subject to seismic action resides in its behaviour beyond elastic limit. Nonlinear dynamic analysis seems to be the most appropriate procedure to obtain more realistic behaviour [1]. However, such analysis requires relatively heavy computation means. Moreover, the selection of proper acceleration records is a serious issue [2,3]. For this reason, seismic codes for instance, Eurocode-8 (EC8) [4], Uniform Building Code [5] and ASCE [6], recommend the use of simplified elastic analysis method. In this approach, the design base shear force is calculated using an elastic pseudo-acceleration response spectrum scaled down by a reduction factor. This factor is used to design the structure at the ultimate limit state by taking into account its nonlinear response [7]. The reduction factor is called behaviour factor ( $q$-factor) in EC8, or, response modification factor ( $R$-factor) in American codes [5]. Based on the elastic analysis, EC8 specifies an upper limit value of $q$-factor for all structures of a given framing type and ductility class, irrespective of the proper characteristics of the structure. This approach, however, under certain circumstances may lead to $q$-factor values not always appropriate if compared with the actual dissipative features of the structure $[8,9]$. This is mostly a consequence of neglecting some parameters that affect the inelastic structural response, in particular, the effect of structural dimensions (height and length) on the local response of structural members.

Previous researches were conducted in order to define the parameters affecting the $q$-factor value [9-11]. Some of these parameters include: bay lengths, irregularity, type of bracing system, type of connections between structural members and seismic intensity. It has been recognized that there are other parameters which may influence the $q$-factor value for other structural typology with different ductility classes requiring more detailed investigations. In this context, the present research proposes investigating the influence of the following parameters: stories and bays number, "Column/Beam" capacity factor, local response of structural members (columns) and structural performance limits, on the $q$-factor value of medium 
ductile SMRFs designed according to European codes $[4,12]$. The $q$-factor components (design reserve strength, redundancy and ductility) are evaluated using pushover analysis.

\section{Provisions of behaviour factor in seismic codes}

In order to develop a better understanding of structural seismic response and provide a formulation of the behaviour factor, ATC3-06 [13] conducted a research program. This research allowed proposing the first formula of the behaviour factor and developed thereafter in $[14,15]$. It leads to an appropriate definition of the behaviour factor, which is based on ductility-dependent component and reserve strength-dependent component. The reserve strength is the product of two factors: the redundancy factor due to the redistribution of internal forces and the design reserve strength factor connected with the design procedure. These components are explicitly considered in the EC8 [4] definition of the $q$-factor for steel structures. The reference $q$-factor assigned to SMRFs in EC8 are 1.5 to 2,4 and $5 \alpha_{u} / \alpha_{1}$ for low (DCL), medium (DCM) and high (DCH) ductility classes, respectively. The $\alpha_{u} / \alpha_{1}$ ratio is related to the redundancy of structure, $\alpha_{1}$ is the first yielding strength of a structural member and $\alpha_{u}$ is the ultimate strength of the whole structure.

In Eurocode-8, the flange and web slenderness limits classify the members with respect to the local ductility of cross-sections into four classes: 1, 2, 3, and 4 which, in turn, determine the overall ductility class of the structure and the value of $q$-factor. Hence, the application of $q$-factor greater than 2 must be combined with sufficient local ductility within dissipative zones. For DCM and $q$-factor equal to 4 , class 1 or 2 cross-sections should be used, whereas for DCH and $q$-factor greater than 4 , only class 1 cross-sections should be employed in dissipative zones. Unlike EC8, most codes, such as Uniform Building Code [5], give $q$-factor value just for two ductility classes with respect to the SMRFs, namely: ordinary and special. For seismic codes that specify $q$-factor value for medium ductile SMRFs, there is no great difference in their numerical values. For example, the $q$-factor of medium ductile regular SMRFs suggested in ASCE [6] is 4.5, which is almost the same as that proposed in EC8 [4].

Thus, it can be seen clearly that the main seismic codes do not give enough precision about the effect of the parameters discussed previously (stories and bays number, "Column/ Beam" capacity, local response of structural members and structural performance limits) on the $q$-factor. The effect of these parameters on the value of $q$-factor is an essential and pressing objective of this study.

\section{Literature review}

Nowadays, the design linear elastic method has been used in most seismic codes. In this method, the critical parameter is the $q$-factor, which plays a paramount role in designing the earthquake load-resisting elements. Because of the importance of $q$-factor on the dynamic response of structure and its relationship with the reserve strength and ductility factors, the parameters that affect this factor have been an important research topic for the last few decades [16-18].

The effect of vibration period on the nonlinear response of frame is of major interest, in particular on the components of $q$-factor. According to Osteraas and Krawinkler [19], the reserve strength factor of steel frames was observed. SMRFs having various bay sizes and heights were subjected to pushover analysis. They found that the reserve strength factor ranged from 8.0 in the short period range to 2.1 at a period of 4.0 seconds. Rahgozar and Humar [20] determined the reserve strength factor of SMRFs, where they showed that this factor decreases as the number of stories and the level of seismic intensity increase. In addition they found that $P$-delta effect has imposed an additional reduction. Mahmoudi and Zaree [21] determined the reserve strength of concentrically braced steel frames. The authors observed that the height of frame makes a slight difference in terms of redundancy factor, while the same parameter has a significant effect on the design reserve strength factor. On the other hand, Kappos [22] studied five reinforced concrete frames, with one to five stories. The author demonstrated that the reserve strength depends on the ductility of structural members. Furthermore, in order to assess the effect of beams-columns semi-rigid connections on the $q$-factor components of steel structures, Balendra and Huang [16] studied SMRFs with 3, 6 and 9 stories having rigid and semirigid beam-column connections. The results indicated that the structures with semi-rigid connections have a lower reserve strength reaching $50 \%$ that of frames with rigid connections. Performing pushover analyses, Kim and Choi [10] determined the $q$-factor of concentric chevron-braced steel frames with different stories number and bay lengths. The authors showed that the $q$-factor components increased as structure height decreased and bay length increased. Fanaie and Dizaj [23] also studied the effect of stories number on the $q$-factor components considering buckling restrained braced frames. They found that the reserve strength and ductility factors are decreased as the number of stories is increased. Kang and Choi [17] performed pushover analysis on SMRFs with 4, 8 and 16 stories to estimate their $q$-factors. The results showed that the calculated $q$-factors have different values with various design parameters, such as the design base shear coefficient $\mathrm{V} / \mathrm{W}$, the framing system and the number of stories. Mondal et al. [18] elaborated a study to assess the $q$-factor of reinforced concrete structures designed following the Indian standards. The authors found that the Indian standard recommends a higher than actual value of $q$-factor. Ferraioli et al. [9] investigated the $q$-factor of high ductile SMRFs designed according to the recent Italian code. They found that the calculated $q$-factor is less than the Italian code value in the case of high-rise frame. 
Previous studies did not consider the effect of "Column/ Beam" capacity and local response of structural members (columns) on the $q$-factor, especially for medium ductile SMRFs. Also, although several studies have been conducted on the influence of stories and bays number on the $q$-factor, but it still remains a topical issue and significant research efforts are required for better clarify its effect on $q$-factor for different structural systems and ductility classes of structures. A detailed methodology for the computation of $q$-factor has been presented in the subsequent section.

\section{Methodology for computation of behaviour factor}

Clear definitions of the $q$-factor are difficult to find in seismic codes, but it is almost generally accepted that this factor simply represents the ratio of the elastic strength demand, i.e. the strength that would be required in the structure, if it were to respond elastically to the design earthquake, to the inelastic strength demand, i.e. the strength required in the structure for it to respond beyond the elastic range but within the selected ductility (and/or displacement) limits [22]. Mazzolani and Piluso [24] addressed various theoretical procedures to compute the $q$-factor, such as the maximum plastic deformation approach and the energy approach. The formulation of the $q$-factor proposed by ATC-34 [15] is the most used currently [9,11,25]. It is expressed as the product of three parameters that significantly influence the seismic response of structures. In this study, the evaluation of the $q$-factor is made by means of the nonlinear static procedure using the formulation of ATC-34 [15]. Hence, the behaviour factor ( $R$-factor in ATC) is defined as:

$$
R=R_{\Omega} \cdot R_{\mu} \cdot R_{\rho} .
$$

In Eq. (1), $R_{\Omega}$ is the design reserve strength factor, $R_{\mu}$ is the ductility factor and $R_{\rho}$ is the redundancy factor. The assessment of these factors can be obtained from the pushover curve or base shear force-roof lateral displacement relationship (see Fig. 1).

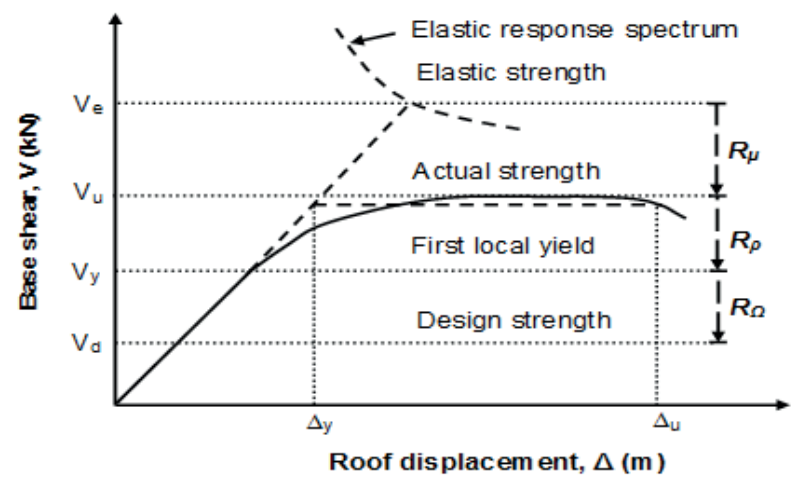

Fig. 1 Base shear force vs. roof lateral displacement relationship

The reserve strength accounts for the fact that the consequences of past seismic have shown that certain buildings structures have resisted well to larger seismic forces than those that they were designed for. This is due mainly to an internal overstrength (reserve strength). This reserve strength depends on several factors including the design approach (e.g. capacity design). The main possible sources of reserve strength that have been reviewed by Rahgozar and Humar [20] and Elghazouli [8] include: the difference between the actual and the design material strength, effect of using discrete member sizes, effect of minimum requirements on member sections in order to meet the stability and serviceability limits and the redistribution of internal forces. The presence of the reserve strength in structures may be classified into two categories: the design reserve strength ( $R_{\Omega}$-factor) and the redundancy ( $R_{\rho}$-factor).

The $R_{\Omega}$-factor is used to quantify the difference between the required and the first yielding strength. It may be defined as the ratio of the first yielding strength $\mathrm{V}_{\mathrm{y}}$ to the design strength $\mathrm{V}_{\mathrm{d}}$ of the structure (Eq. (2)).

$$
R_{\Omega}=\frac{\mathrm{V}_{\mathrm{y}}}{\mathrm{V}_{\mathrm{d}}} .
$$

The $R_{\rho}$-factor is related to the configuration of the structure. This factor is defined in terms of the ultimate strength $V_{u}$ and the first yielding strength $\mathrm{V}_{\mathrm{y}}$ of the structure (see Eq. (3)).

$$
R_{\rho}=\frac{\mathrm{V}_{\mathrm{u}}}{\mathrm{V}_{\mathrm{y}}} .
$$

The displacement ductility $\mu$ is a measure of the global nonlinear response of a structure, commonly used to represent the capacity of structure to dissipate energy, and its effects, considered through the $R_{\mu}$-factor. It is particularly important for steel structures since the beneficial effect of ductility is supposed to come from different sources [26]. In the last three decades, several studies focused on the evaluation of the $R_{\mu}$-factor. The works by Nassar and Krawinkler [27] and Fajfar [28] are significant and are frequently referred to. The authors developed relationships for the determination of ductility factor by relating the $R_{\mu}$ and $\mu$ parameters. In this study, the most used relationships [11,29] developed by Fajfar [28] are used to calculate the $R_{\mu}$-factor. Thus,

$$
\begin{gathered}
R_{\mu}=(\mu-1) \frac{T}{T_{c}}+1 \text { for } T<T_{c} . \\
R_{\mu}=\mu \text { for } T \geq T_{c} .
\end{gathered}
$$

Where $T$ is the vibration fundamental period of the structure and $T_{c}$ is the characteristic period of ground motion. $\mu$ is defined as the ratio of the ultimate displacement $\Delta_{u}$ corresponding to the selected performance level of failure and the yield displacement $\Delta_{y}$ of the structure. Thus,

$$
\mu=\frac{\Delta_{\mathrm{u}}}{\Delta_{\mathrm{y}}} .
$$

Yield displacement is judged through an idealization of base shear force vs. roof lateral displacement relationship (pushover or capacity curve). For this purpose, a bilinear curve is fitted to the capacity curve. For bilinear idealization of the capacity 
curve, it is necessary to simplify the capacity curve for an elastic perfectly plastic regime. The initial stiffness of the idealized system is determined in such a way so that the areas under the actual and idealized capacity curves are the same [4].

In the Eurocode-8 [4], the $q$-factor for steel structures is defined as follows:

$$
q=q_{0} \frac{\alpha_{\mathrm{u}}}{\alpha_{1}}
$$

In which $q_{0}$ is the basic value of the behaviour factor, the $\alpha_{u} / \alpha_{1}$ ratio is the redundancy factor. A comparison between Eq. (1) and Eq. (7) leads to: $\alpha_{u} / \alpha_{1}=R_{\rho}$ and $q_{0}=R_{\mu} R_{\Omega}$ [9].

\section{Numerical analysis}

In order to evaluate the structural response curve (capacity curve) for use in the determination of the $q$-factor, two different methods of analysis are generally used: the nonlinear static pushover analysis and the nonlinear dynamic analysis. Owing to the simplicity of the former method compared to the latter one, the pushover analysis is used in the present study.

\subsection{Choice of structures}

In the current work, a number of medium ductile regular SMRFs having 3, 6, 9 and 12 stories with 3 and 6 bays five meters each and a height of $3 \mathrm{~m}$ for each floor are modeled to evaluate the impact of various parameters on the $q$-factor. These frames are called (xSyB) with $\mathrm{x}$ the number of stories and $\mathrm{y}$ the number of bays (3S3B; 6S3B; 9S3B; 12S3B; 3S6B; 6S6B; 9S6B and 12S6B). The frames have been designed in accordance with the provisions of structural Eurocodes [4,12] on the basis of a peak ground acceleration (PGA) equal to $0.35 \mathrm{~g}$, damping coefficient $\xi=5 \%$, soil class $\mathrm{B}$ and behaviour factor $q_{\text {design }}=$ 4.0 (DCM). Gravity load on the beams is assumed to be equal to $27.5 \mathrm{kN} / \mathrm{m}$ (dead and live loads of floors), while steel members are made of grade S235. Data of the frames, including storey number and beam and column sections are presented in 「Table 1 taken from Kamaris et al. [30]. In that table, expressions of the form, e.g., 280-360(1-4) + 260-330(5-6) mean that the first four stories have columns with HEB280 sections and beams with IPE360 sections, whereas the next two higher stories have columns with HEB260 sections and beams with IPE330 sections.

The complete formation of a mechanism is achieved when plastic hinges are formed at the base of columns and at the ends of beams. According to this work, a parameter that impacts the nonlinear behaviour of SMRFs is the "Column/Beam" capacity factor ai, which is the ratio of the average of the plastic moments of first-storey columns $M_{R C, 1, a v}$ to the average of plastic moments of beams of all stories of the frame $M_{R B, a v}$. Thus,

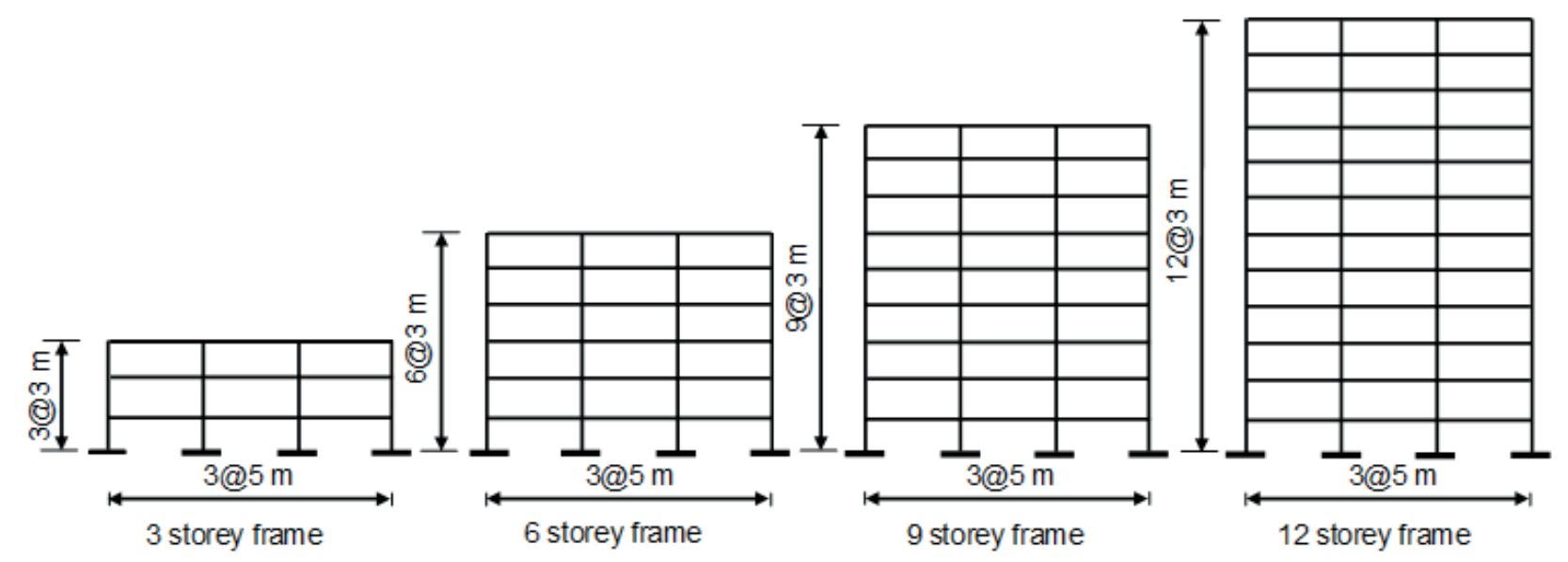

Fig. 2 The studied frames (with 3 bays)

Table 1 SMRFs considered in parametric studies

\begin{tabular}{llll}
\hline Storey number & $\mathrm{i}$ & ai & Columns: (HEB) \& Beams: (IPE) \\
\hline \multirow{3}{*}{3 stories } & 1 & 1.30 & $240-330(1-3)$ \\
& 2 & 1.60 & $260-330(1-3)$ \\
& 3 & 1.90 & $280-330(1-3)$ \\
& 1 & 1.60 & $300-360(1-4)+260-330(5-6)$ \\
6 stories & 2 & 1.97 & $320-360(1-4)+280-330(5-6)$ \\
& 3 & 2.27 & $360(1-4)+300-330(5-6)$ \\
9 stories & 1 & 2.19 & $400-360(1)+400-400(2-5)+360-360(6-7)+340-330(8-9)$ \\
& 2 & 2.93 & $400-360(1)+400-400(2-3)+400-450(4-5)+360-400(6-7) 340-400(8-9)+340-360(10)+340-330(11-12)$ \\
& 3 & 2.60 & $450-360(1)+450-400(2-3)+450-450(4-5)+400-450(6-7) 360-400(8-9)+360-360(10)+360-330(11-12)$ \\
& 1 & 3.00 & $500-360(1)+500-400(2-3)+500-450(4-5)+450-450(6-7) 400-400(8-9)+400-360(10-11)+400-330(12)$ \\
\hline
\end{tabular}


Table 2 Modal periods and mass ratios of analyzed SMRFs (with 3 bays)

\begin{tabular}{|c|c|c|c|c|c|c|c|c|c|c|c|}
\hline Storey number & $\mathrm{i}$ & ai & $\mathrm{T}_{1}(\mathrm{~s})$ & $\mathrm{T}_{2}(\mathrm{~s})$ & $\mathrm{T}_{3}(\mathrm{~s})$ & $\mathrm{M}^{* 1}$ & $\mathrm{M}^{* 2}$ & $\mathrm{M}^{* 3}$ & $\mathrm{~V}_{\mathrm{d}}(\mathrm{kN})$ & $\mathrm{W}(\mathrm{kN})$ & $\mathrm{V}_{\mathrm{d}} / \mathrm{W}$ \\
\hline \multirow{3}{*}{3 stories } & 1 & 1.30 & 0.73 & 0.23 & 0.13 & 0.86 & 0.11 & 0.03 & 200.43 & 1285.11 & 0.1560 \\
\hline & 2 & 1.60 & 0.69 & 0.21 & 0.12 & 0.85 & 0.11 & 0.03 & 212.27 & 1288.05 & 0.1648 \\
\hline & 3 & 1.90 & 0.65 & 0.19 & 0.11 & 0.84 & 0.12 & 0.03 & 225.96 & 1291.00 & 0.1750 \\
\hline \multirow{3}{*}{6 stories } & 1 & 1.60 & 1.22 & 0.41 & 0.23 & 0.81 & 0.11 & 0.04 & 285.21 & 2590.62 & 0.1101 \\
\hline & 2 & 1.97 & 1.17 & 0.38 & 0.21 & 0.81 & 0.11 & 0.04 & 296.67 & 2598.47 & 0.1142 \\
\hline & 3 & 2.27 & 1.13 & 0.37 & 0.20 & 0.80 & 0.11 & 0.05 & 308.12 & 2605.73 & 0.1182 \\
\hline \multirow{3}{*}{9 stories } & 1 & 2.19 & 1.55 & 0.54 & 0.30 & 0.80 & 0.11 & 0.04 & 338.87 & 3924.78 & 0.0863 \\
\hline & 2 & 2.43 & 1.52 & 0.53 & 0.29 & 0.80 & 0.11 & 0.04 & 345.96 & 3932.63 & 0.0880 \\
\hline & 3 & 2.93 & 1.46 & 0.51 & 0.28 & 0.79 & 0.11 & 0.04 & 361.45 & 3944.21 & 0.0916 \\
\hline \multirow{3}{*}{12 stories } & 1 & 2.60 & 1.90 & 0.66 & 0.38 & 0.79 & 0.11 & 0.03 & 370.85 & 5264.83 & 0.0704 \\
\hline & 2 & 3.00 & 1.78 & 0.63 & 0.35 & 0.79 & 0.10 & 0.03 & 397.01 & 5284.45 & 0.0751 \\
\hline & 3 & 3.63 & 1.72 & 0.60 & 0.33 & 0.79 & 0.10 & 0.04 & 412.75 & 5306.82 & 0.0778 \\
\hline
\end{tabular}

$$
\mathrm{ai}=\frac{M_{R C, 1, a v}}{M_{R B, a v}} .
$$

Table 2 presents the natural periods and the modal mass ratios $\mathrm{M}^{* 1}, \mathrm{M}^{* 2}, \mathrm{M}^{* 3}$ of the first three mode shapes of the dynamic modal analysis, where it can be observed that the total mass participating in the fundamental mode of the studied frames is more than $75 \%$. This allows using the pushover analysis in which its application is globally based on the fundamental mode. Also in Table 2 the design base shear force $\mathrm{V}_{\mathrm{d}}$ and the weight $\mathrm{W}$ of the studied frames are reported. Only frames with three bays are shown in Fig. 2 and Table 2.

\subsection{Nonlinear Static Pushover Analysis (NSPA)}

A two-dimensional finite element model of each frame which includes load-deformation relationship of all members at their ends is created in the computer program SAP2000 [31] to perform NSPA. For columns, the effect of the axial load is considered using a model of $\mathrm{N}-\mathrm{M}$ interaction diagram. As Annex B of EC8 only defines the plastic rotation capacity for columns and beams with dimensionless axial load not greater than 0.30 , the plastic rotation capacity of columns and beams has been computed according to Tables 5-6 and 5-7 of FEMA 356 (Fig. 3) [32]. For columns, a combined P-M hinge model (bending moment $\mathrm{M}$ and axial force $\mathrm{N}$ in the Eurocodes and $\mathrm{P}$ in the American Codes) implemented in SAP2000 [31] has been employed for the nonlinear analyses.

In this analysis, the geometric and mechanical characteristics of steel members are considered. Also, all sources of geometrical nonlinearity have been included, namely $P$-delta and large displacement effects. According to FEMA 356 [32], the panel zone area dimensions were not considered in the analysis as the expected shear strength of panel zones exceeds the flexural strength of the beams at a beam-to-column connection and the stiffness of the panel zone is over 10 times larger than the flexural stiffness of the beam. Consequently, connections were assumed to be rigid.

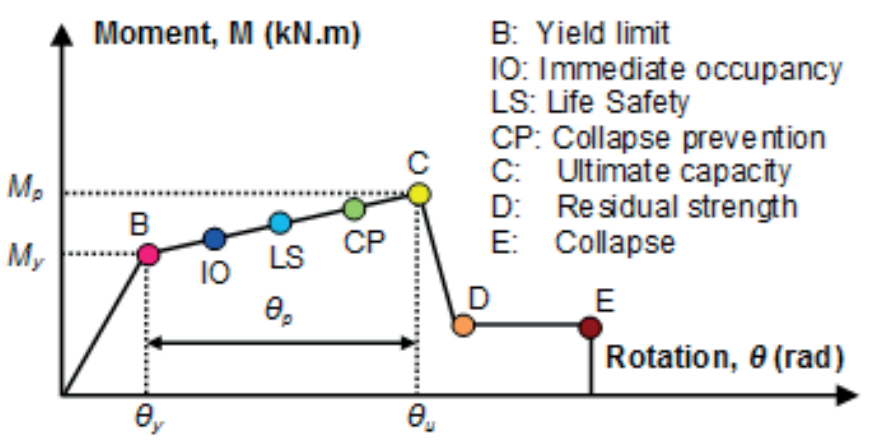

Fig. 3 Moment-rotation relationship of a cross section [32]

The frames are subjected to two horizontal load patterns, a uniform pattern UD, whereby lateral forces are proportional to the total mass at each floor level, and an inverted triangular pattern TD, in which seismic forces are proportional to the product of floor mass and storey height [33]. The horizontal loads are distributed along their height whose intensity increases incrementally until a mechanism is formed (structural performance limit or failure mode). It leads to construct the pushover curve which is used to obtain the $q$-factor components. The structural performance limits are described in the following section.

\subsection{Structural Performance Limits}

The structural performance limit is a critical parameter in the definition of the $q$-factor, because this factor is associated to the selected failure mode of the structure. In general, the failure mode is based on the damage indices such as the inter-story drift ratio ID or the plastic rotation capacity [34]. In many investigations, several values for the ID are considered as the primary global failure mode. Balendra and Huang [16], Massumi and Mohammadi [35], Louzai and Abed [11] used upper limits of ID equal to $2 \%, 2.5 \%$ and $3 \%$ of the inter-storey height (hs), respectively. The EC8 does not specify drift criteria or plastic rotation capacity to define the failure mode or the ultimate limit state corresponding to which the values of $q$-factor are recommended. As a consequence, two 
performance limits (PLi) are used in this study to define the failure mode. These are: PL1, defined by an upper limit of ID equal to $3 \%$ hs and PL2, related to the global ultimate capacity GUC of the frame (maximum base shear or ultimate plastic rotation at the base of the first-storey columns).

Furthermore, the formation of plastic hinges in columns is an undesirable mechanism (soft-storey) in the frame structure. For this reason, a performance limit PL3 related to the first column to reach ultimate load capacity ULC (point C in Fig. 3) is considered to show the effect of the column local response on the global behaviour and the $q$-factor of the studied SMRFs.

\subsection{Validation of Pushover Curve}

In this study, the pushover curve plotted using DRAIN2DX computer program of SMRF studied by Karavasilis et al. [36] was used to validate the pushover curve obtained by SAP2000 [31]. SMRF with bay width equal to $6 \mathrm{~m}$ and storey height equal to $3 \mathrm{~m}$ is considered. The first three stories have columns with HEB340 sections and beams with IPE450 sections, whereas the last three (upper) stories have columns with HEB280 sections and beams with IPE360 sections. Steel members are made of grade S235. The comparison between the two curves represented in Fig. 4, shows that the two curves are very close.

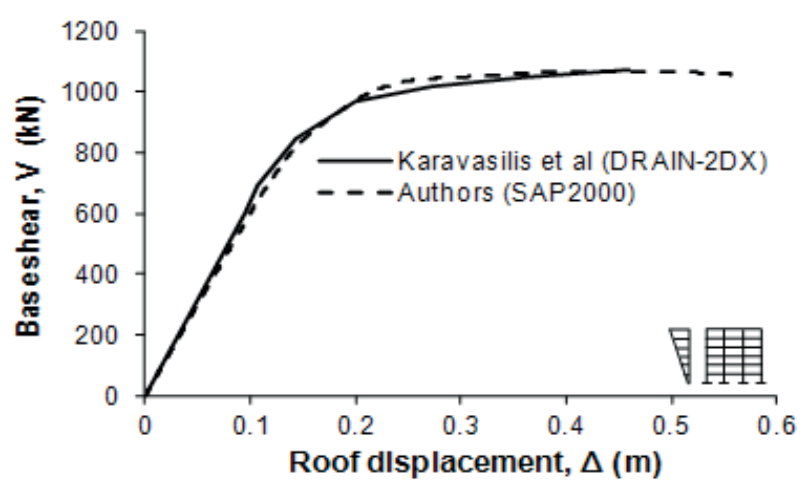

Fig. 4 Pushover curves of the analyzed frame

\section{Results and Discussion}

The numerical results of the studied SMRFs are presented and discussed in this section. Nonlinear static pushover analyses using inverted triangular and uniform load patterns distribution were carried out to compute the $q$-factor components, such as the design reserve strength $R_{\Omega}$, redundancy $R_{\rho}$, and ductility $R_{\mu}$ factors. The effects of stories and bays number, "Column/Beam" capacity factor ai, local response of structural members (columns) and structural performance limits on the $q$-factor are investigated.

Pushover curves of the studied frames with the three values of "Column/Beam" capacity factor (a1, a2 and a3) are presented in Fig. 5. The considered performance limits (PL1, PL2 and PL3) are marked on the pushover curve. It can be seen in Fig. 5 that the lateral displacement at PL2 (global ultimate capacity) of low and medium-rise frames (3, 6 and 9-storey) is greater than that at PL1 (3\% hs). However, for high-rise frame (12-storey) the difference is smaller (see Figs. 5d, 5h). The comparison between the results obtained for PL1 and PL2 is very important because the latter is the limit beyond which there is a failure of the whole structure, which means that the plastic behaviour of the structure is completely exhausted. Thus, the previous observations permit to deduce that the limit PL1 is acceptable as controlling failure for high-rise frames, whereas for low and medium-rise frames, it implies to limit their nonlinear behaviour. On the other hand, Fig. 5 indicates that the risk of local column instability, represented by PL3 whose cause is due to the loss of rigidity after reaching its ultimate resistance capacity, increases as the number of stories increases. Moreover, for all frames, the base shear force increases with the increase of "Column/Beam" capacity factor ai. This is due to the increase in the dimensions of columns cross-sections (hence an increase of their lateral resistance), which will absorb more forces.

As example, Fig. 6 shows the distribution of plastic hinges at PL2 for the studied frames with 3 bays (for the minimum value of capacity factor ai). It appears in Fig. 6, that there is a good distribution of energy dissipation along the height and across the length of the low and medium-rise frames. However, for the high-rise frame, the distribution of plastic hinges tends to concentrate in only one-half of the entire frame because of the appearance of premature plastic hinges of ultimate load capacity (PL3) at the base of columns sections. This distribution could be explained by the sensitivity of the frame to the $P$-delta effect, which is influenced by the large lateral displacement and the high value of axial force at the columns sections.

In order to compute the $q$-factor components, pushover curve of the studied SMRFs are obtained from NSPA. However, relevant information collected from the plot must first be idealized. Bilinear idealization provides essential components, namely, significant yield base shear and displacement, as well as predetermined base shear force and ultimate displacement related to the failure mode of the structure (PL1 and PL2). The $R_{\Omega}, R_{\rho}$ and $R_{\mu}$ factors are calculated as discussed in section 4 . The following sections provide and discuss the results of computing $q$-factor considering the effects of stories and bays number, structural performance limits, "Column/ Beam" capacity factor and local response of structural members (columns). 

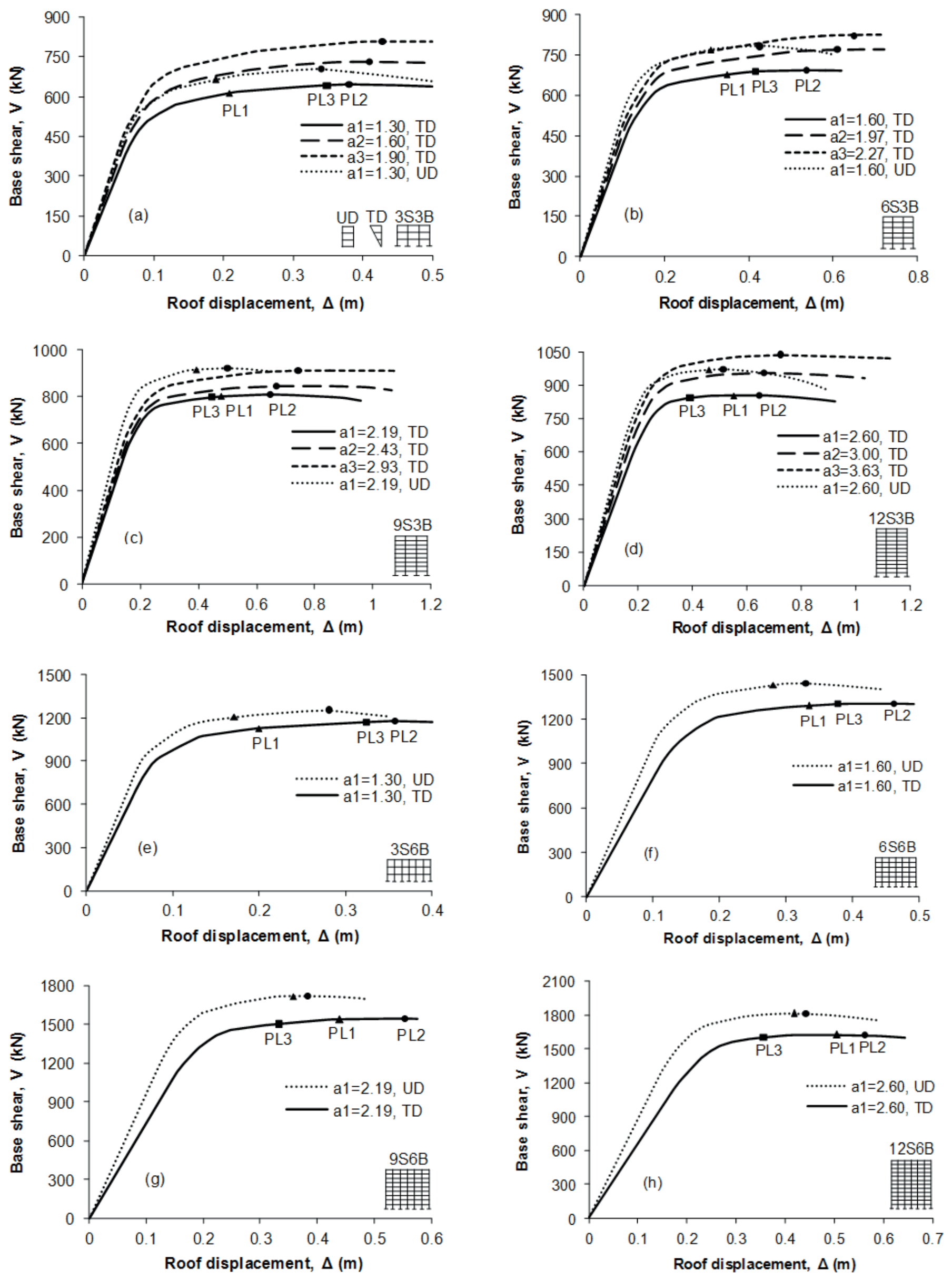

Fig. 5 Pushover curves of the analyzed frames 


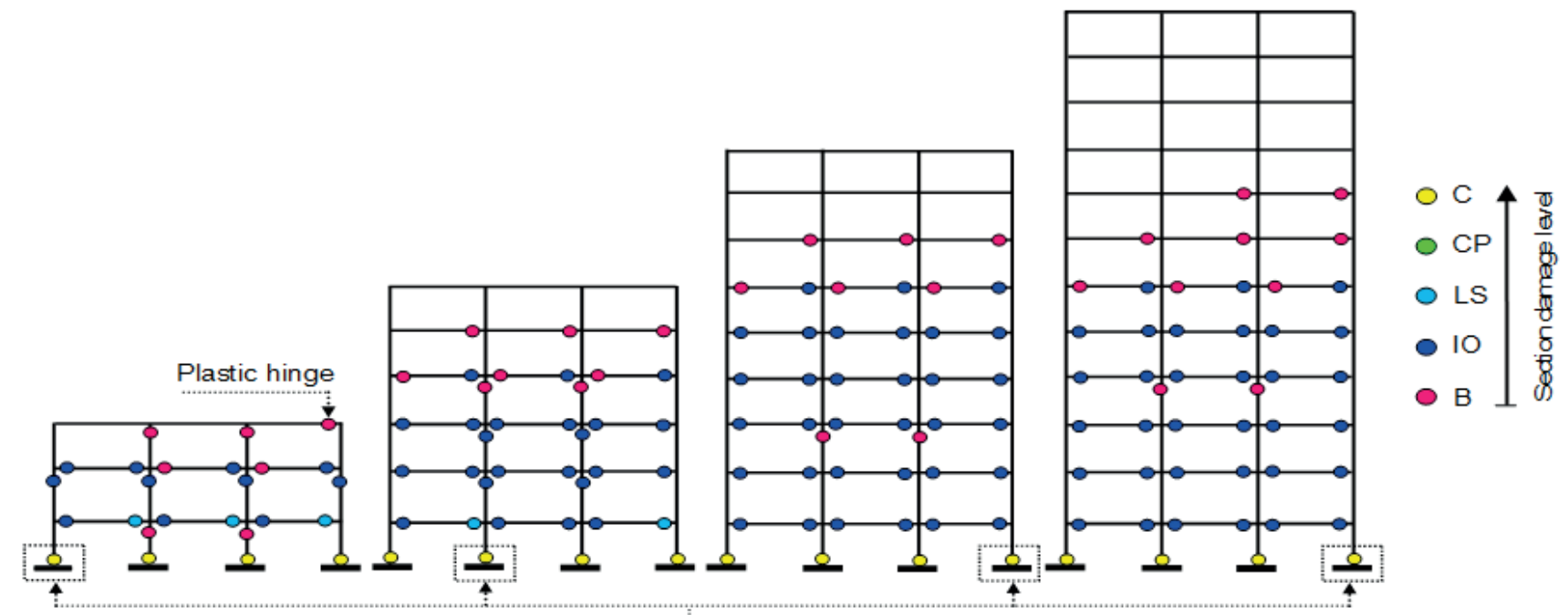

First column to reach ultimate load capacity (PL3)

Fig. 6 Plastic hinges distribution at PL2 for the studied frames with 3 bays (for the minimum value of ai) under inverted triangular distribution
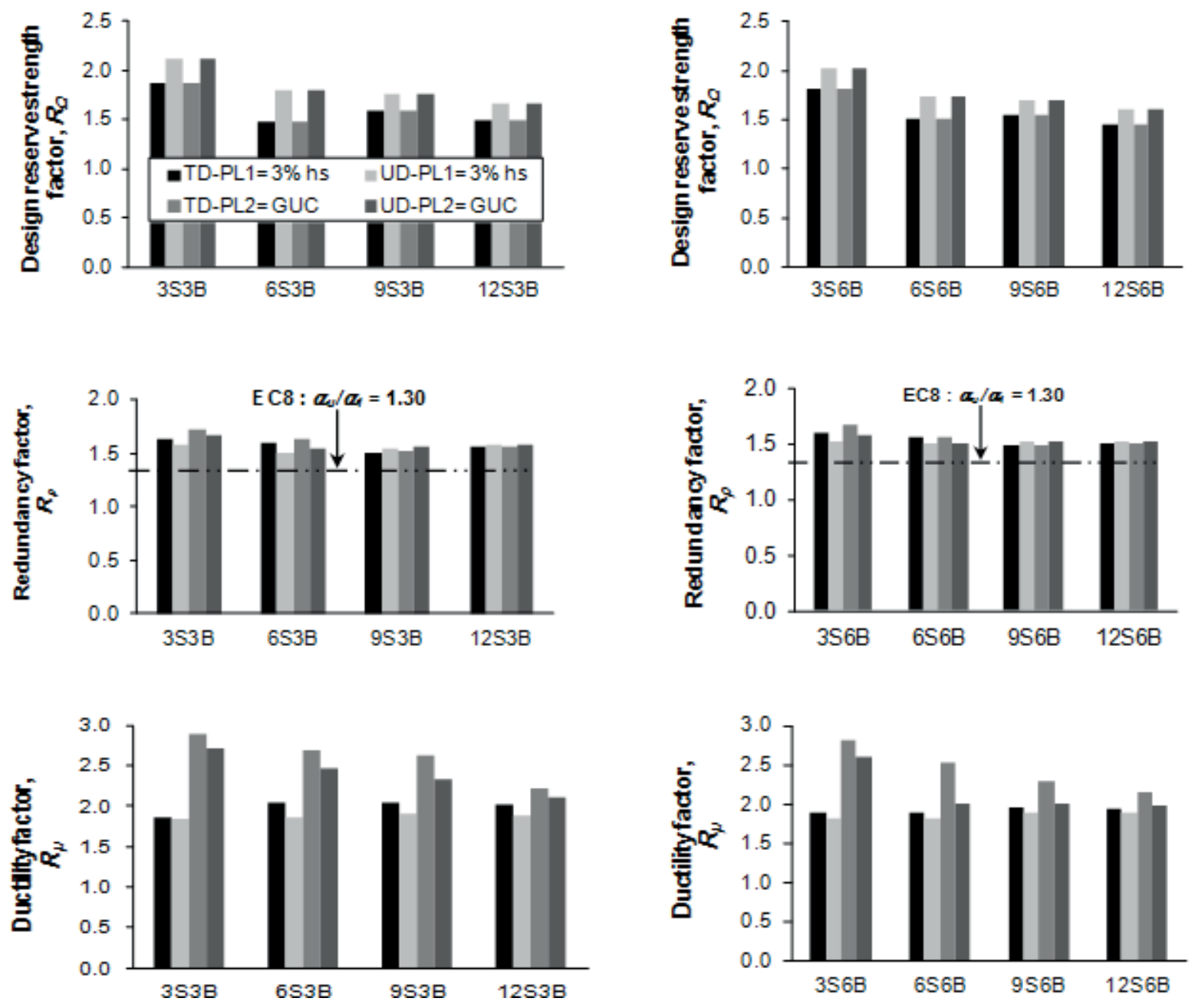

Fig. 7 Behaviour factor components of the studied frames 


\subsection{Stories and bays number effect on $q$-factor}

Figure 7 shows the variation of the $q$-factor components according to the stories and bays number. In particular, the design reserve strength factor $R_{\Omega}$, the redundancy factor $R_{\rho}$, and the ductility factor $R_{\mu}$ resulting from pushover analysis using two lateral load patterns distribution (inverted triangular and uniform). The performance limits PL1 and PL2 are considered for computing the $q$-factor.

In Figure 7, it can be noticed that the number of stories influence the value of $R_{\Omega}$-factor. The greater value of this factor is obtained for low-rise frame. This result could be explained by the fact that the magnitude of design reserve strength depends on the relative values of the gravity and earthquake loads. Comparison between the earthquake base shear to the total gravity load ratio of the studied SMRFs (see Table 2) shows that the highest $\mathrm{V}_{\mathrm{d}} / \mathrm{W}$ ratio is observed for the 3-storey frame, reflecting the high stiffness and the efficiency of this frame in resisting lateral forces. The lowest $\mathrm{V}_{\mathrm{d}} / \mathrm{W}$ ratio is observed for the 12-storey frame as a result of the high total gravity load. Furthermore, the $R_{\Omega}$-factor is little sensitive to the number of bays and the lateral load patterns. The $R_{\rho}$-factor has almost a constant value for all studied frames. The average value of $R$-factor is 1.58 and 1.54 for frames with 3 and 6 bays, respectively. These values are higher than that recommended by EC8: $R_{\rho}\left(\alpha_{u} / \alpha_{1}\right)=1.30$ for high ductile SMRFs.

The $R_{\mu}$-factor is obtained from the idealized capacity curve. In the light of the obtained results (Fig. 7), it is clear that the $R_{\mu}$-factor decreases as the number of stories increases for PL2. Similar tendency but less pronounced is observed when the bays number increases. However, the value of this factor calculated for PL1 is almost constant.

Figure 8 shows the variation of the calculated $q$-factor as a function of the stories and bays number, the load patterns and the performance limits. The $q$-factor value specified by EC 8 is represented by a horizontal dashed line $\left(q_{\text {design }}=4\right.$ for medium ductile regular SMRFs). In general, the number of stories has significant influence on the $q$-factor value. It is clear that the value of $q$-factor decreases as the number of stories increases. Furthermore, the increasing of the number of bays imposes an additional reduction. For such frames, small differences have been found between the $q$-factor values obtained under the inverted triangular and the uniform distributions.

\subsection{Structural performance limit effect on $q$-factor}

The effect of structural performance limits on the $q$-factor is discussed here. $R_{\Omega}, R_{\rho}$ and $R_{\mu}$ factors are obtained for PL1 and PL2. The pushover plots clearly show that, for all studied SMRFs, PL2 is reached after PL1 (that is, for a larger roof displacement). Based on the pushover plots (and their bilinear idealization), $\mathrm{V}_{\mathrm{u}}$ values come out to be the same as those for PL1, $V_{d}$ values do not change. There are very minor variations from PL1 values for $\Delta_{y}$ values. $\Delta_{u}$ values for PL2, as mentioned earlier, are larger than corresponding PL1 values.

Among the various components of $q$-factor, $R_{\Omega}$ and $R_{\rho}$ factors obtained for PL2 remain the same as in PL1. On the contrary, the $R_{\mu}$-factor values come out to be higher (Fig. 7). In fact, for lowrise frame, the $R_{\mu}$-factor value obtained for PL2 is higher than that calculated for PL1. However, for high-rise frame, the $R_{\mu}$-factor value for PL2 comes out to be almost the same as that for PL1. This is due to the high axial force at the base of first-storey columns, which imposed a reduction on the ductility of the frame leading to the mechanism of soft-storey (an unstable structure).

The $q$-factor value calculated for PL2 is higher than that obtained for PL1 (Fig. 8), in particular, for low and medium-rise frame. This variation in $q$-factor values signifies that the studied SMRFs are not very consistent in terms of a member rotation capacity (performance level), especially the performance of first-storey columns. Furthermore, in the case of high-rise frame, the calculated $q$-factor is almost equal to the EC 8 specified value and less than that assigned by ASCE [6]. It also can be indicated that the obtained results show that the $q$-factor value depends on the structural performance limits that define the failure criteria, which are not taken into account by EC8. Moreover, the outcome of the present study is in good agreement with the numerical work reported by Mondal et al. [18] for reinforced concrete frames, where they found that the considered structural performance limit for controlling global failure related to an inter-storey drift tends to underestimate the actual value of $q$-factor.

\subsection{Structural members resistance effect on $q$-factor}

In this section, the effects of "Column/Beam" capacity factor ai (or strong-column/weak-beam concept) and local response of columns, in particular first-storey columns on the $q$-factor value are discussed.
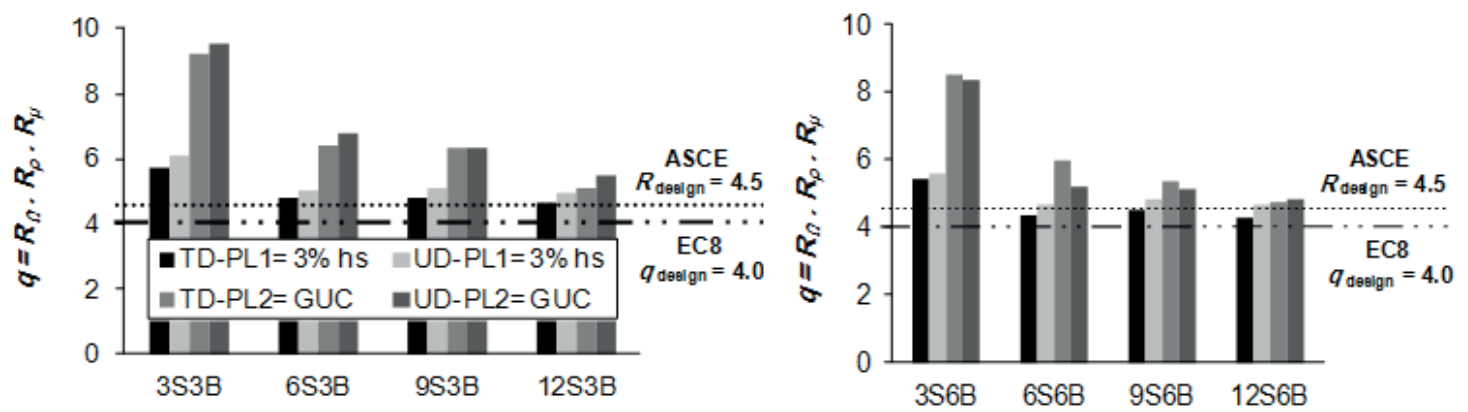

Fig. 8 Behaviour factors of the studied frames 

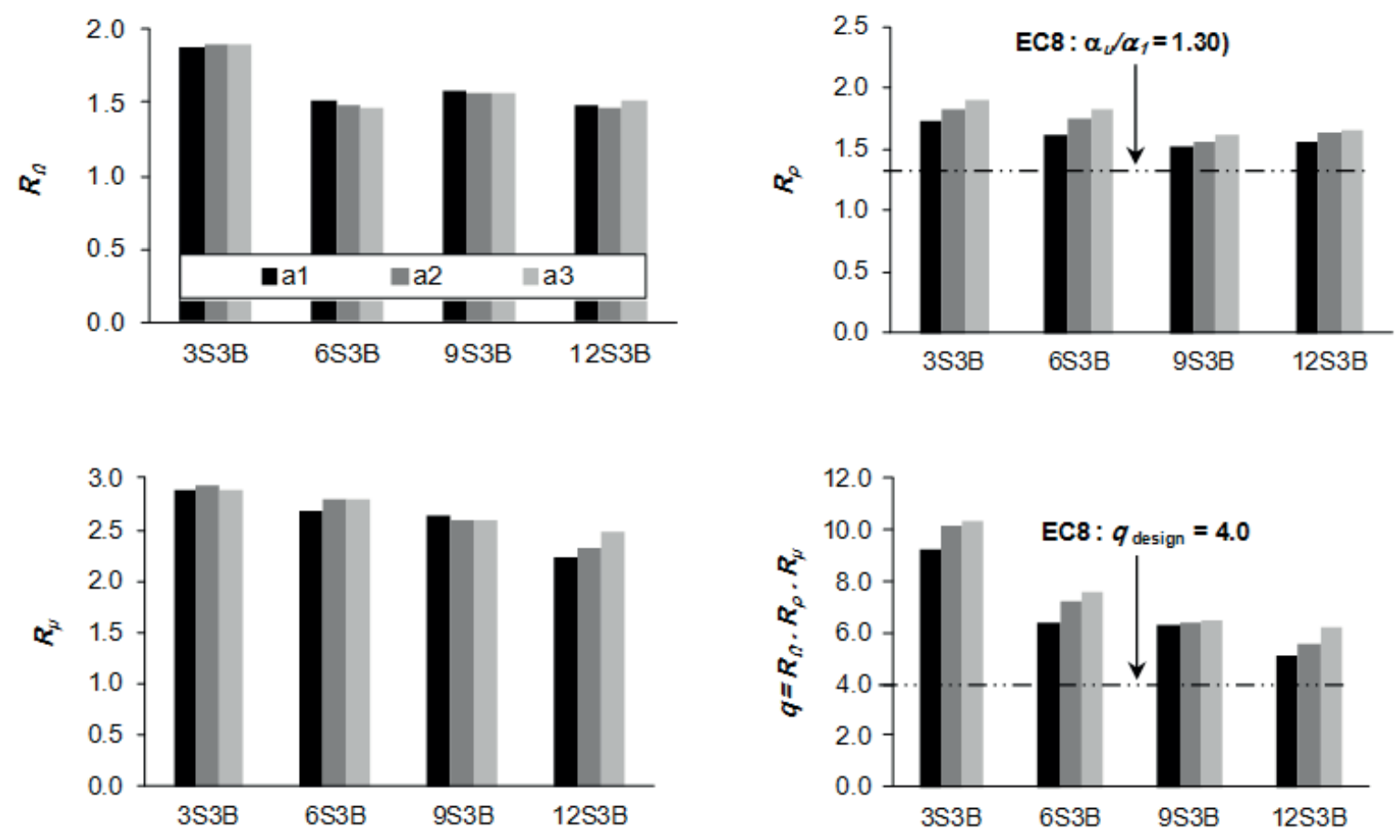

Fig. 9 Behaviour factors of the studied frames at PL2

In order to show the effects of "Column/Beam" capacity factor ai and local response of columns on the $q$-factor value, the columns sections of the studied SMRFs (with the minimum value of capacity factor a1) are increased two times for each of the frames (3, 6, 9 and 12-storey) to get three different values of capacity factor ai (see †Table 1). These values are not the same for all frames since the effect of gravity loads on the selection of column section increases with an increasing number of stories. The performance limit PL2 is considered to compute $q$-factor components. PL2 is used to avoid the underestimation of the $R_{\mu}$-factor of low and medium-rise frames as concluded in section 6.2.

The variation of $q$-factor and its components as a function of "Column/Beam" capacity factor is given in Fig. 9. It can be observed that the $q$-factor components are little sensitive to the capacity factor, this latter consequently makes relatively modest difference in terms of $q$-factor value. This is due to the fact that the failure of the studied SMRFs occurs as the plastic hinges appearance at the base column sections, which leads to limit their nonlinear behaviour. It also can be observed that, although the capacity factor values of low-rise frames are smaller than those of high-rise frames, however, the $q$-factor values of low-rise frames are greater than those of high-rise frames. This is mostly due to the increase of the axial force at the base of first-storey columns sections as the stories number increases, which leads to a great reduction in their ultimate load capacity. In order to clarify this effect, the first column section to reach ultimate load capacity (PL3) in each of the frames (3, 6, 9 and 12-storey) is represented in Fig. 5. Comparing the occurrence of PL3, it is noted that the increasing of the number of stories (axial force) provides a premature appearance of column plastic hinge of PL3. This leads to a premature failure of the frame. The appearance of such premature failure (soft-storey mechanism) confirms the importance of design methods focusing on the performance based plastic design PBPD of steel frames [37,38].

Figure 10a shows the variation of the $q$-factor as a function of the "Column/Beam" capacity factor ai and the ratio of the axial force $N$ to the plastic axial capacity $N_{p l}$ of first columns sections that reach their ultimate load capacity PL3 (first storey columns). According to this figure, it is clear that the $q$-factor decreases with the increase of the axial force ratio. This is due to the local failure of first-storey columns sections (loss of stiffness after reach PL3) deriving from the effect of high axial force that greatly reduces their plastic moment capacity and, consequently, limits the global inelastic response of the structure.

Figure $10 \mathrm{~b}$ shows the effect of the axial force ratio $\left(N / N_{p l}\right)$ on the bending moment ratio $\left(M / M_{p l}\right)$ and the ultimate rotation capacity $\theta_{u}$ of first columns sections that reach their ultimate load capacity PL3 of the studied SMRFs (for the minimum value of "Column/Beam" capacity factor a1). The bending moment ratio represents the bending moment $M$ to the plastic moment capacity $M_{p l}$. It is observed that the plastic moment and the ultimate rotation capacity of columns sections are strongly influenced by the value of the axial force ratio. As the number of stories increases, the axial force at the base sections of first-storey columns increases. This imposed a great reduction on the plastic moment and the ultimate rotation capacity of columns sections. It leads to limit the ductility of the frame, which causes a reduction on the reserve strength factor and, consequently decreasing the value of $q$-factor. 

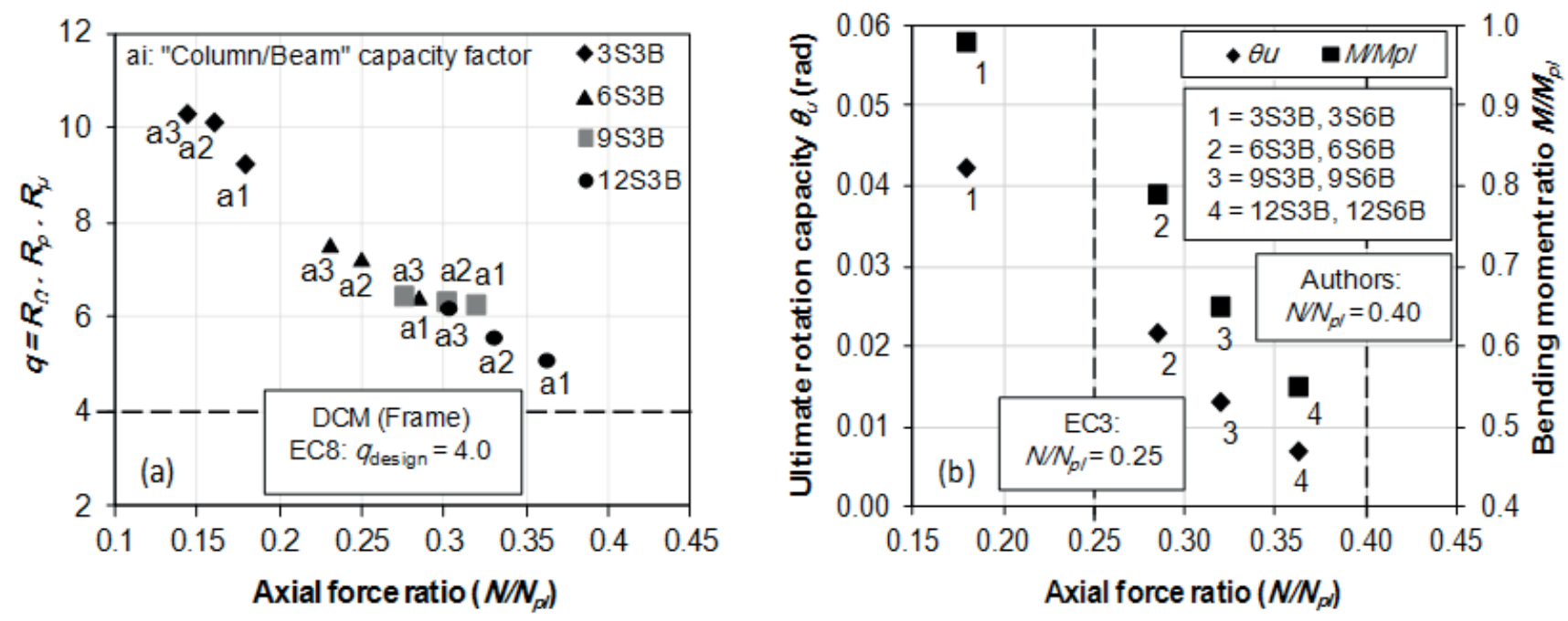

Fig. 10 Effect of "Column/Beam" capacity factor and local response of column on behaviour factor

On the basis of the above results, the studied medium ductile SMRFs present a weak point in their lateral ductility. In fact, this structural typology is not able to provide sufficient ductility as far as the height of the frame or the axial force increases. These results confirm the importance of the criteria given in the EC3 [12], which requires the accounting of the axial force effect on the plastic resistance moment of the cross-section when the axial force ratio $\left(N / N_{p l}\right)$ is greater than 0.25 . This criterion is represented by a vertical dashed line in the Fig. 10b. As it has already been pointed out, the $q$-factor of the studied SMRFs is significantly influenced by the local response of columns sections. For this reason, a criterion related to the local ductility of columns sections $\left(N / N_{p l}<0.40\right)$ has been proposed based on the results of these investigations. The main aim of the proposed criterion is to avoid the overestimation of the $q$-factor value and to optimize the agreement between the actual $q$-factor value and that specified in EC8.

In Figure 10a, the estimated $q$-factors for the studied SMRFs with different values of the axial force ratio are compared with the EC8 specified value. For high-rise frames, the result shows that the decrease of the axial force ratio increase the value of $q$-factor and, consequently, avoid the risk of the overestimation of the $q$-factor value in the design. This result leads explicitly to confirm the efficiency of the proposed criterion on the $q$-factor value.

\section{Conclusions}

A detailed study concerned the medium ductile steel moment-resisting frames (SMRFs) designed according to the European codes (EC3 and EC8) has been conducted. In this context, the effects of number of stories, number of bays, "Column/Beam" capacity factor, local response of columns and structural performance limits are considered. The partial components (design reserve strength $R_{\Omega}$, redundancy $R_{\rho}$ and ductility $R_{\mu}$ ) of the behaviour factor ( $q$-factor) are evaluated using pushover analysis with two load patterns (inverted triangular and uniform distribution). On the basis of the previous results, the following conclusions can be stated:

1. Design reserve strength, redundancy, ductility and behaviour factors decrease when the number of stories increases. Similar tendency but less pronounced is observed when the number of bays increases.

2. When the number of stories increases, the axial force at the first-storey columns sections increases. This leads to reduce the plastic moment resistance and the rotation capacity of the columns. Thus, the values of the reserve strength and ductility factors decrease, which consequently reduce the value of $q$-factor.

3 . The average value of the $R_{\rho}$-factor related to the redundancy is 1.58 and 1.54 for frames with 3 and 6 bays respectively. These values are higher than that provided by EC8: $\alpha_{u} / \alpha_{1}=$ 1.30 for high ductile SMRFs.

4. The failure modes observed in the studied frames are different. The performance PL1 defined by an upper limit of an inter-storey drift equal to $3 \% \mathrm{hs}$ is acceptable as controlling failure for high-rise frames (12-storey), whereas for low and medium-rise frames (3, 6 and 9-storey) it implies to limit their nonlinear behaviour, consequently under-estimation of the $q$-factor value.

5. The "Column/Beam" capacity factor ai makes relatively modest difference in terms of $q$-factor, because the appearance of plastic hinges at the base of first-storey columns limits the redistribution of internal forces of these frames typology. 6. The $q$-factor value specified by EC8: $q_{d e s i g n}=4$ for medium ductile SMRFs is less than those calculated for the studied frames. This result mostly comes out from the analysis of 3, 6 and 9-storey frames. For 12-storey frame, the value of $q$-factor is around 4.

7. A local ductility criterion based on the control of the axial force level and related to the local response of columns sections has been proposed to avoid the overestimation of $q$-factor value. 
These investigations are concentrated to the effect of the stories and bays number, "Column/Beam" capacity, local response of the structural members (columns) and structural performance limits on the behaviour factor of medium ductile regular steel frames without braces. It has been pointed out that significant research efforts are required to evaluate the same factor for these frames type and frames with braces considering other parameters that may influence their inelastic behaviour, such as irregularity of frames in plan and elevation, unequal bay lengths and type of connections (beam-column and column base-to-foundation).

\section{Acknowledgement}

This work has been prepared as a result of a research carried out at Hassiba Benbouali University, Chlef, Algeria and Clermont Auvergne University, Clermont-Ferrand, France for the completeness of the $\mathrm{PhD}$ degree of the first Author. The authors would like to thank the Ministry of Higher Education and Scientific Research for the financial support.

\section{References}

[1] Mahmoudi, M., Teimoori, T., Kozani, H. "Presenting displacement-based nonlinear static analysis method to calculate structural response against progressive collapse". International Journal of Civil Engineering, 13 (4), pp. 478-485. 2015. http://ijce.iust.ac.ir/article-1-1015-en.html

[2] Izadinia, M., Rahgozar, M. A., Mohammadrezaei, O. "Response modification factor for steel moment-resisting frames by different pushover analysis methods". Journal of Constructional Steel Research, 79, pp. 83-90. 2012. 10.1016/j.jcsr.2012.07.010

[3] Chaulagain, H., Rodrigues, H., Spacone, E., Guragain, R., Mallik, R., Varum, H. "Response reduction factor of irregular RC buildings in Kathmandu valley". Earthquake Engineering and Engineering Vibration, 13 (3), pp. 455-470. 2014. 10.1007/s11803-014-0255-8

[4] EN 1998-1-1. "Design of structures for earthquake resistance-Part 1: General rules, seismic actions and rules for buildings". CEN, European Committee for Standardization, Brussels (Belgium). 2005.

[5] UBC (Uniform Building Code). "Vol.2: Structural engineering design provisions". Whittier, California. 1997.

[6] ASCE/SEI 7-10. "Minimum Design Loads for Building and Other Structures". American Society of Civil Engineers, New York. 2010.

[7] Fanaie, N., Shamlou, S. O. "Response modification factor of mixed structures". Steel and Composite Structures, 19(6), pp.1449-1466. 2015. 10.12989/scs.2015.19.6.1449

[8] Elghazouli, A. Y. "Assessment of European seismic design procedures for steel framed structures". Bulletin of Earthquake Engineering, 8, pp. 65-89. 2010. 10.1007/s10518-009-9125-6

[9] Ferraioli, M., Lavino, A., Mandara, A. "Behaviour Factor of Code-Designed Steel Moment-Resisting Frames". International Journal of Steel Structures, 14(2), pp. 243-254. 2014. 10.1007/s13296-014-2005-1

[10] Kim, J., Choi, H. "Response modification factors of chevron-braced frames". Engineering Structures, 27(2), pp. 285-300. 2005. 10.1016/j. engstruct.2004.10.009

[11] Louzai, A., Abed, A. "Evaluation of the seismic behavior factor of reinforced concrete frame structures based on comparative analysis between non-linear static pushover and incremental dynamic analyses". Bulletin of Earthquake Engineering, 13 (6), pp. 1773-1793. 2015. 10.1007/s10518014-9689-7
[12] EN 1993-1-1. "Design of steel structures-Part 1: General rules and rules for buildings". CEN, European Committee for Standardization, Brussels (Belgium). 2005.

[13] ATC3-06. "Tentative provisions for the development of seismic regulations for buildings". Applied Technology Council, Redwood City, California. 1978.

[14] ATC-19. "Structural response modification factors". pp. pp. 5-32. Applied Technology Council, Redwood City, California. 1995. https:// www.slideshare.net/raselduet/atc-19-structural-response-modificationfactor-by-applied-technology-council-1995

[15] ATC-34. "A critical review of current approaches to earthquake-resistant design". Applied Technology Council, Redwood City, California. 1995. https://www.atcouncil.org/pdfs/atc34toc.pdf

[16] Balendra, T., Huang, X. "Overstrength and Ductility Factors for Steel Frames Designed According to BS 5950". Journal of Structural Engineering ASCE, 129(8), pp. 1019-1035. 2003. 10.1061/(ASCE)07339445(2003)129:8(1019)

[17] Kang, C. K., Choi, B. J. "New Approach to Evaluate the Response Modification Factors for Steel Moment Resisting Frames". International Journal of Steel Structures, 11, pp. 275-286. 2011. 10.1007/s13296-0113003-1

[18] Mondal, A., Ghosh, S., Reddy, G. R. "Performance-based evaluation of the response reduction factor for ductile RC frames". Engineering Structures, 56, pp. 1808-1819. 2013. 10.1016/j.engstruct.2013.07.038

[19] Ostraas, J. D., Kraeinkler, H. "Strength and Ductility Considerations In Seismic Design". Report No.90, The John A. Blume Earthquake Engineering Center, Department of Civil and Environmental Engineering, Stanford University, California, USA. 1990. https://stacks.stanford.edu/ file/druid:cb239mm7088/TR90_Osteraas.pdf

[20] Rahgozar, M. A., Humar, J. L. "Accounting for overstrength in seismic design of steel structures". Canadian Journal of Civil Engineering, 25(1), pp. 1-15. 1998. 10.1139/197-045

[21] Mahmoudi, M., Zaree, M. "Evaluating the overstrength of concentrically braced steel frame systems considering members post-buckling strength". International Journal of Civil Engineering, 9(1), pp. 57-62. 2011. http://ijce.iust.ac.ir/article-1-301-en.html

[22] Kappos, A. J. "Evaluation of behaviour factors on the basis of ductility and overstrength studies". Engineering Structures, 21(9), pp. 823-835. 1999. 10.1016/S0141-0296(98)00050-9

[23] Fanaie, N., Dizaj, E. A. "Response modification factor of the frames braced with reduced yielding segment BRB". Structural Engineering and Mechanics, 50(1), pp. 1-17. 2014. 10.12989/sem.2014.50.1.001

[24] Mazzolani, F. M., Piluso, V. "Theory and Design of Seismic Resistant Steel Frames". E \& FN Spon, An imprint of Chapman \& Hall, London, 1996.

[25] Abdollahzadeh, G., Banihashemi, M. "Response modification factor of dual moment-resistant frame with buckling restrained brace (BRB)". Steel and Composite Structures, 14(6), 621-636. 2013. 10.12989/ scs.2013.14.6.621

[26] Dehghani, E., Hamidi, S. A., Tehrani, F. M., Goyal, A., Mirghaderi, R. "New Practical Approach to Plastic Analysis of Steel Structures". Periodica Polytechnica Civil Engineering, 59(1), pp. 27-35. 2015. 10.3311/ PPci.7578

[27] Nassar, A., Krawinkler, H. "Seismic demands for SDOF and MDOF systems". John A Blume Earthquake Engineering Center Technical Report 95. Stanford Digital Repository. Stanford University, California, USA. 1991. https://stacks.stanford.edu/file/druid:qt582bc4669/TR95_Nassar.pdf

[28] Fajfar, P. "A nonlinear analysis method for performance based seismic design". Earthquake Spectra, 16 (3), pp. 573-592. 2000. 10.1193/1.1586128

[29] Mahmoudi, M., Zaree, M. "Determination the response modification factors of buckling restrained braced frames". Procedia Engineering, 54, pp. 222-231. 2013. 10.1016/j.proeng.2013.03.020 
[30] Kamaris, G. S., Vallianatou, Y. M., Beskos, D. E. "Seismic damage estimation of in-plane regular steel moment resisting and x-braced frames". Bulletin of Earthquake Engineering, 10(6), pp. 1745-1766. 2012. 10.1007/s10518-012-9387-2

[31] SAP2000. "Linear and nonlinear static and dynamic analysis of three-dimensional structures". Computers and Structures Inc. (CSI), Berkeley (CA). 2010.

[32] FEMA 356. "Prestandard and Commentary for the Seismic Rehabilitation of Buildings". American Society of Civil Engineers for the Federal Emergency Management Agency, Washington. 2000.

[33] Gholipour, M., Alinia, M. M. "Considerations on the Pushover Analysis of Multi-Story Steel Plate Shear Wall Structures". Periodica Polytechnica Civil Engineering, 60(1), pp. 113-126. 2016. 10.3311/PPci.7706

[34] Soltangharaei, V., Razi, M., Gerami, M. "Comparative Evaluation of Behavior Factor of SMRF Structures for Near and Far Fault Ground Motions". Periodica Polytechnica Civil Engineering, 60(1), pp. 75-82. 2016. 10.3311/PPci.7625
[35] Massumi, A., Mohammadi, R. "Structural redundancy of 3D RC frames under seismic excitations". Structural Engineering and Mechanics, 59(1), pp. 15-36. 2013. 10.12989/sem.2016.59.1.015

[36] Karavasilis, T. L., Bazeos, N., Beskos, D. E. "Maximum displacement profiles for the performance based seismic design of plane steel moment resisting frames". Engineering Structures, 28(1), pp. 9-22. 2006. 10.1016/j.engstruct.2005.06.021

[37] Banihashemi, M. R., Mirzagoltabar, A. R., Tavakoli, H. R. "Development of the performance based plastic design for steel moment resistant frame". International Journal of Steel Structures, 15(1), pp. 51-62. 2015. 10.1007/s13296-015-3004-6

[38] Xiong, E., He, H., Cui, F., Bai, L. "Performance-Based Plastic Design Method for Steel Concentrically Braced Frames Using Target Drift and Yield Mechanism". Periodica Polytechnica Civil Engineering, 60(1), pp. 127-134. 2016. 10.3311/PPci.7383 